\title{
Thyroid Stimulating Hormone Stability in Patients Prescribed Synthetic or Desiccated Thyroid Products: A Retrospective Study
}

\author{
Rolake Kuye, PharmD \\ Catherine Riggs, PharmD \\ Jordan King, PharmD, MS \\ Rachel Heilmann, PharmD \\ Deanna Kurz \\ Jessica Milchak, PharmD \\ Kaiser Permanente, Denver, Colorado
}

\begin{abstract}
The purpose of this retrospective matched-cohort study was to evaluate the stability of thyroid stimulating hormone (TSH) in patients using synthetic compared with desiccated thyroid products. Patients using a thyroid product for the treatment of hypothyroidism were matched 1:1 on age, sex, race/ethnicity, and had a follow-up period of 3 years after the index date. The primary outcome was percent of in-range TSH values. Over 3 years, TSH values in both groups were inrange $79 \%$ of the time $(P=0.905)$. Our results showed no difference in longitudinal TSH stability between desiccated thyroid products and synthetic levothyroxine.
\end{abstract}

Ann Fam Med 2020;18:452-454. https://doi.org/10.1370/afm.2545.

\section{INTRODUCTION}

$\mathrm{H}$ ypothyroidism is a common endocrine disorder that affects approximately $5 \%$ of the population. ${ }^{1}$ Both synthetic and desiccated thyroid are used in the treatment of hypothyroidism. Synthetic levothyroxine $\left(\mathrm{T}_{4}\right)$ is considered the treatment of choice due to its ability to provide stable blood levels and minimal fluctuations in $\mathrm{T}_{4} \cdot{ }^{2-4}$ Despite this, there are patients and practitioners who prefer desiccated thyroid. ${ }^{3}$ Although there are a few small trials reporting greater symptom and quality-of-life improvements with desiccated thyroid compared with levothyroxine, there is a lack of data comparing objective measures of hypothyroidism management between the 2 modalities over an extended period. Therefore, the purpose of this study is to evaluate the longitudinal stability of thyroid stimulating hormone (TSH) in patients prescribed levothyroxine compared with desiccated thyroid for the management of hypothyroidism.

\section{METHODS}

\section{Study Design and Setting}

This retrospective matched cohort study was conducted at Kaiser Permanente Colorado (KPCO) and approved by the KPCO institutional review board. Electronic medical, pharmacy, and laboratory records were used to identify patients and treatments, and outcomes were obtained from the KPCO Virtual Data Warehouse.

\section{Study Patients}

Patients aged $\geq 18$ years receiving levothyroxine or desiccated thyroid for the treatment of hypothyroidism between January 1, 2005 and December 31, 2015 were eligible for inclusion (Table 1). To ensure chronic medication use, we first identified the earliest thyroid product dispensed during the evaluation period. We then identified second dispensing of the same product occurring at least 1 year later, defined as the index date. Data was collected for 3 years after the index date. Patients were required to
Catherine Riggs

580 Mohawk Drive

Boulder, CO 80303

catherine.s.riggs@kp.org 
maintain KPCO membership for the duration of the study. Patients were excluded if they had the following comorbid conditions: panhypopituitarism, post-radioiodine therapy, history of thyroid cancer, pregnancy, Graves' disease, or Hashimoto's thyroiditis. Patients were also excluded if they were prescribed more than 1 agent for treatment of hypothyroidism. Patients prescribed levothyroxine who met inclusion criteria were matched 1:1 on age, sex, and race/ethnicity to patients prescribed desiccated thyroid.

\section{Outcome Variables}

The primary outcome was the percent of euthyroid (0.320-5.500 uIU/mL) TSH values. Secondary outcomes included visit-to-visit TSH variability, percent

Table 1. Baseline Characteristics at Index Date and Results

\begin{tabular}{|c|c|c|c|}
\hline & $\begin{array}{l}\text { Desiccated } \\
\text { Thyroid } \\
(n=435)\end{array}$ & $\begin{array}{c}\text { Synthetic } \\
\text { Levothyroxine } \\
(n=435)\end{array}$ & $P$ Value \\
\hline Age, y (mean, 95\% Cl) & $63.4(12.68)$ & $63.4(12.68)$ & Matched \\
\hline Female No. (\%) & $392(90.1)$ & $392(90.1)$ & Matched \\
\hline Race, No. (\%) & & & Matched \\
\hline Non-Hispanic White & $363(83.4)$ & $363(83.4)$ & Matched \\
\hline Non-Hispanic Black & $5(1.1)$ & $5(1.1)$ & \\
\hline Hispanic & $22(5.1)$ & $22(5.1)$ & \\
\hline Other & $45(10.3)$ & $45(10.3)$ & \\
\hline TSH (mean, 95\% Cl) & $2.4(0.18)$ & $3.4(0.27)$ & 0.001 \\
\hline $\mathrm{BMI}\left(\mathrm{kg} / \mathrm{m}^{2}\right)$ (mean, 95\% Cl) & $27.55(5.94)$ & $28.62(6.64)$ & 0.032 \\
\hline Systolic BP (mmHg) (mean, 95\% Cl) & $127.31(16.28)$ & $126.98(16.09)$ & 0.772 \\
\hline Diastolic BP (mmHg) (mean, 95\% Cl) & $74.61(8.59)$ & $75.14(8.07)$ & 0.366 \\
\hline $\mathrm{HgbA}_{1 \mathrm{c}}($ mean, 95\% Cl) & $6.67(0.94)$ & $7.18(1.30)$ & 0.041 \\
\hline $\begin{array}{l}\text { Random glucose (mg/dL) } \\
\quad \text { (mean, } 95 \% \mathrm{Cl})\end{array}$ & $97.36(20.52)$ & $97.51(25.56)$ & 0.961 \\
\hline \multicolumn{4}{|l|}{ Comorbidities, No. (\%) } \\
\hline Hypertension & $135(31.0)$ & $150(34.5)$ & 0.312 \\
\hline Myocardial infarction & $<6$ & $<6$ & 0.722 \\
\hline Diabetes mellitus & $37(8.5)$ & $46(10.6)$ & 0.356 \\
\hline Heart failure & $8(1.8)$ & $10(2.3)$ & 0.812 \\
\hline Atrial fibrillation & $12(2.8)$ & $11(2.5)$ & 1 \\
\hline \multicolumn{4}{|l|}{ Cholesterol (mg/dL) (mean, 95\% Cl) } \\
\hline High density lipoprotein & $60.62(17.55)$ & $59.97(16.81)$ & 0.715 \\
\hline Low density lipoprotein & $114.14(31.91)$ & $115.77(34.92)$ & 0.64 \\
\hline Triglycerides & $141.42(82.22)$ & $147.05(74.20)$ & 0.489 \\
\hline Total cholesterol & $201.98(35.41)$ & $204.74(39.44)$ & 0.479 \\
\hline \multicolumn{4}{|l|}{ Results } \\
\hline $\begin{array}{l}\text { Percent of TSH values in range, } \\
\text { (mean, } 95 \% \mathrm{Cl})\end{array}$ & $79.3(76.6-82.1)$ & $79.1(76.4-81.7)$ & 0.905 \\
\hline Visit-to-visit TSH, (SD of TSH) & $1.44(1.33-1.54)$ & $1.25(1.15-1.36)$ & 0.015 \\
\hline $\begin{array}{l}\text { Percent of patients with } 100 \% \text { of TSH } \\
\text { values in range, (mean, } 95 \% \text { CI) }\end{array}$ & $60.0(55.8-64.1)$ & $59.8(55.7-63.9)$ & 0.951 \\
\hline $\begin{array}{l}\text { Number of TSH laboratories obtained } \\
\text { per patient over the 3-year study } \\
\text { period (mean, IQR) }\end{array}$ & $3(3-5)$ & $4(3-5)$ & 0.578 \\
\hline
\end{tabular}

of patients with TSH values in-range throughout the entire follow-up period, and number of TSH values.

\section{Statistical Analysis}

Mean (standard deviation) or count (percent) was used to describe the baseline characteristics of the final study population at index date. Differences in baseline characteristics between the 2 cohorts were compared using $\chi^{2}$ tests for categorical end points and 1-way ANOVA for continuous end points. Multivariableadjusted regression models were calculated to determine the association of desiccated thyroid product type and each outcome. All models were adjusted for the following covariates: hypertension, previous myocardial infarction, diabetes, heart failure, number of TSH laboratory values during follow up, and use of a medication known to cause a significant increase or decrease in the serum concentration of thyroid products.

Logistic regression was used to determine the association with in-range TSH values; linear regression was used to determine the association with visit-to-visit TSH variability; Poisson regression was used to determine the association with count of TSH laboratory values obtained during the 3-year follow-up period. Because each patient could contribute more than 1 TSH value in the follow-up period to the analysis, standard errors were calculated allowing for intragroup correlation when applicable. To improve the interpretability of regression coefficients, after fitting each regression model we obtained predicted values of the outcomes for synthetic levothyroxine and desiccated thyroid users.

\section{RESULTS}

A total of 870 patients were included in the study. Patients prescribed desiccated thyroid had lower body mass index (BMI) $(P=0.032)$, hemoglobin $\mathrm{A}_{1 \mathrm{c}}(P=0.041)$, and baseline TSH value $(P=0.001)$ compared with 
those prescribed levothyroxine. There was no difference in the primary outcome between the 2 groups as TSH values were in-range $(0.320-5.500 \mathrm{uIU} / \mathrm{mL})$ $79.3 \%$ of the time compared with $79.1 \%$ of the time for levothyroxine and desiccated thyroid patients, respectively $(P=0.905)$. Patients prescribed levothyroxine had significantly less visit-to-visit TSH variability than those prescribed desiccated thyroid (1.25 vs $1.44, P=0.015)$; however, $60 \%$ of patients in both groups had all of their TSH values measured during the study period in-range $(P=0.951)$. Patients prescribed synthetic levothyroxine had a median of 4 TSH laboratories obtained during the study period compared with 3 for patients prescribed desiccated thyroid $(P=0.578)$.

\section{DISCUSSION}

The results of this study show no difference between synthetic levothyroxine and desiccated thyroid in the percent of TSH values in-range over 3 years of followup. This was an unanticipated finding given concerns for variability between batches of desiccated thyroid cited by national guidelines. ${ }^{3,4}$ This study did demonstrate less visit-to-visit TSH variability with levothyroxine. For providers targeting a tighter TSH goal in certain patients, the decreased TSH variability with levothyroxine could be clinically meaningful.

Regarding study limitations, this was a retrospective chart review in which we were unable to account for confounding variables such as adherence, differences in prescriber practice between agents, or concurrent medications that could have affected TSH. We were also unable to assess subjective outcomes of hypothyroidism management. There was a statistically significant difference between the baseline TSH value of patients prescribed desiccated thyroid $(2.4 \mathrm{uIU} / \mathrm{mL})$ compared with those prescribed synthetic levothyroxine $(3.4(\mathrm{uIU} / \mathrm{mL})$, although both groups were within the KPCO TSH reference range.

This study adds to the limited body of evidence regarding the stability of levothyroxine and desiccated thyroid. A previous study noted that TSH levels remained within reference range for 12 weeks in patients treated with either levothyroxine or desiccated thyroid..$^{5}$ This study showed that after 3 years, TSH values in both groups remained within reference ranges approximately $80 \%$ of the time.

To read or post commentaries in response to this article, see it online at https://www.AnnFamMed.org/content/18/5/452.

Key words: thyroid stimulating hormone (TSH); levothyroxine; desiccated thyroid; stability; hypothyroidism; thyrotropin, thyroxine, thyroid (USP)

Submitted December 6, 2018; submitted, revised, December 13, 2019; accepted December 17, 2019.

Previous presentation: Presented at Mountain States Conference; May 10, 2018; Salt Lake City, Utah.

\section{References}

1. The thyroid and you: coping with a common condition. NIH Medline Plus. 2012;2012(7):22-23.

2. Cooper DS. Thyroid hormone treatment: new insights into an old therapy. JAMA. 1989;261(18):2694-2695.

3. Garber J. Clinical practice guidelines for hypothyroidism in adults: cosponsored by the American Association of Clinical Endocrinologists and the American Thyroid Association. Endocr Pract. 2012; 18(6):988-1028.

4. Jonklaas J. Guidelines for the treatment of hypothyroidism: prepared by the American Thyroid Association Task Force on Thyroid Hormone Replacement. Thyroid. 2014;24(12):1670-1751.

5. Hoang TD, Olsen CH, Mai VQ, Clyde PW, Shakir MK. Desiccated thyroid extract compared with levothyroxine in the treatment of hypothyroidism: a randomized, double-blind, crossover study. J Clin Endocrinol Metab. 2013;98(5):1982-1990. 